Chapman University

Chapman University Digital Commons

Communication Faculty Articles and Research

School of Communication

9-21-2017

\title{
Watching Online Videos At Work: The Role of Positive and Meaningful Affect for Recovery Experiences and Well-Being at the Workplace
}

Sophie Janicke

Chapman University, janicke@chapman.edu

Diana Rieger

University of Mannheim

Leonard Reinecke

Johannes Gutenberg Universitat, Mainz

Winston Connor III

University of Arkansas

Follow this and additional works at: https://digitalcommons.chapman.edu/comm_articles

Part of the Business Administration, Management, and Operations Commons, Communication Technology and New Media Commons, Mass Communication Commons, Organizational Behavior and Theory Commons, Other Business Commons, Other Communication Commons, $\underline{\text { Social Media }}$ Commons, and the Work, Economy and Organizations Commons

\section{Recommended Citation}

Janicke, S. H., Rieger, D., Reinecke, L., \& Connor, W. III. (2018). Watching online videos at work: The role of positive and meaningful affect for recovery experiences and well-being at the workplace. Mass Communication and Society, 21(3): 345-367. doi: 10.1080/ 15205436.2017 .1381264 


\section{Watching Online Videos At Work: The Role of Positive and Meaningful Affect for Recovery Experiences and Well-Being at the Workplace}

\section{Comments}

This is an Accepted Manuscript of an article published in Mass Communication and Society, volume 21, issue 3, in 2018, available online at DOI: 10.1080/15205436.2017.1381264. It may differ slightly from the final version of record.

\section{Copyright}

Taylor \& Francis 
Watching Online Videos At Work: The Role of Positive and Meaningful Affect for Recovery Experiences and Well-Being at the Workplace

\author{
Sophie H. Janicke \\ Chapman University \\ Diana Rieger \\ University of Mannheim \\ Leonard Reinecke \\ Johannes Gutenberg University Mainz \\ Winston Connor III \\ University of Arkansas
}

PREPRINT

This paper has been accepted for publication in Mass Communication and Society. 


\begin{abstract}
This study extends research on the relationship between hedonic and eudaimonic entertainment and its potential for recovery experiences and aspects of well-being (e.g., Rieger, Reinecke, Frischlich, \& Bente, 2014). With the broad notion of what hedonic and eudaimonic media can entail, this research focused on unique affective experiences, namely positive affect, and an expanded concept of meaningful affect (including elevation and gratitude). An online experiment with 148 full time employees in the US was conducted to investigate the unique role of positive and meaningful affect eliciting Youtube videos (compared to neutral control video) on recovery experiences and vitality and work satisfaction in the work context. A path model suggests that meaningful videos predicted mastery recovery experiences, whereas positive affect predicted psychological detachment and relaxation experiences. In addition, mastery recovery experiences predicted vitality, whereas relaxation experiences predicted satisfaction with work, indicating a unique potential of the consumption of meaningful and positive affect inducing Youtube videos at work for workplace well-being.
\end{abstract}

Keywords: eudaimonic and hedonic entertainment, recovery experiences, well-being, work context, online videos 


\section{Watching Online Videos At Work: The Role of Positive and Meaningful Affect for Recovery Experiences and Well-Being at the Workplace}

Stress is a common phenomenon for the American population, with the average American scoring a 4.9 on a 10 point scale with 10 being "a great deal of stress" according to a recent study conducted by the American Psychological Association in 2014 (APA report, n.d.). To reduce the negative effects of work-related stress, time to recover is one of the most important components (Geurts \& Sonnentag 2006; Lundberg, 2005). Recovery, which is defined as "the process that restores the individual's energetic and mental resources" (Zijlstra, Cropley and Rydstedt, 2014, p. 244) has mainly been researched in the field of organizational psychology.

Recently, researchers in the field of media psychology started to investigate the role media play in recovery experiences after work. Several scholars showed that different forms of entertainment experiences, including interactive, non-interactive, hedonic (i.e., purely pleasurable) and eudaimonic (i.e., meaningful) entertainment can impact various forms of recovery experiences as well as well-being (Rieger et al., 2014; Reinecke, 2009a, 2009b, Reinecke, Klatt, \& Krämer, 2011). This research, however, was limited in several ways: A) It mostly induced work strain artificially in a laboratory setting and tested the recovery effects in samples of students who typically do not suffer from work-related exhaustion to the same extent that employed people do. B) The past research differentiated broadly between hedonic and eudaimonic entertainment but failed to investigate specific media stimuli that elicit a particular set of emotions. C) It focused only on one specific indicator of subjective wellbeing, namely vitality. Based on these limitations, our study seeks to extend this work by a) applying the framework of media-related recovery outside the laboratory into a workplace 
setting, b) investigating the specific facets of eudaimonic drivers of recovery in greater depths (namely an expanded concept of meaningful affect including elevation and gratitude, cf. Algoe \& Haidt, 2009) and c) exploring work satisfaction as another concept of subjective well-being. Specifically, we will explore the distinct roles of eudaimonic and hedonic media experiences for the recovery experiences of relaxation, psychological detachment, and mastery (Sonnentag \& Fritz, 2007) as well as their relationship with subjective well-being in a work setting.

\section{Recovery at work}

At work, employees are constantly confronted with tasks that require their attention. Over time, cognitive and physical resources are depleted which leads to psychological and physical fatigue (Sluiter, deCroon, Meijman et al., 2003). To restore mental and energetic resources people need to recover from demanding work and off-work activities (Zijlstra, Cropley \& Rydstedt, 2014) to avoid long-term stress and negative health consequences (Meijman \& Mulder, 1998). Thus, recovery periods are necessary for both physical and psychological health and well-being (Craig \& Cooper, 1992). Research has shown that activities that contrast the work task (e.g., sports) as well as low effort activities (e.g., socializing, watching TV) are resource-providing and positively related to the recovery process (Sonnentag \& Zijlstra, 2006). And in fact, listening to music (44\%), exercising or walking (43\%), and watching TV/movies for more than 2 hours a day (40\%) are mentioned to be among the most common stress reduction activities for Americans (APA report, n.d.).

Sonnentag and Fritz (2007) distinguished between four different types of recovery experiences that all address different ways depleted resources can be replenished. They consist of: a) psychological detachment, which includes a mental and physical distancing from 
work tasks (i.e., stop thinking about work related tasks), b) relaxation, which refers to the lowering of psychophysiological activation and a re-establishing of positive affect, c) mastery experiences, which consist of taking on new challenges and mastering new skills, which result in replenishing of internal resources such as self-efficacy and positive moods, and d) control, which refers to the freedom to choose activities voluntarily at one's discretion which in turn promote feelings of autonomy and competence.

Ample research demonstrates the relationship between the four dimensions of recovery and the reduction in psychological and physiological work stress (e.g., Siltaloppi, Kinnunen \& Feldt, 2009; Sonnentag, Binnewies, \& Mojza, 2008), and increased self-reported job performance (Binnewies, Sonnentag, \& Mojza, 2010). Most studies about recovery from work focus on activities off-work (external), while less attention has been paid to recovery activities at work (internal) (van Hooff, Geurts, Beckers, Kompier, 2011). However, knowing about the regularity with which people engage in cyberloafing during work, amounting up to $24 \%$ of one's working hours (= 1.92 hours in an $8 \mathrm{~h}$ work day, Websense, n.d.), the question arises, how the personal use of computers during work may impact recovery experiences.

Using the web for personal purposes during work, often referred to as cyberslacking or cyberloafing, is a common phenomenon, with research indicating that approximately $70 \%$ $80 \%$ of employees who use computers at work are prone to engage in this activity (Coker, 2011; Garrett \& Danziger, 2008). A lot of research has focused on the negative effects of cyberloafing in the workplace (Greenfield \& Davis, 2002; Mastrangelo, Everton, \& Jolton, 2006). Other research, however, has shown no detrimental (Garrett \& Danziger, 2008b) and even beneficial effects of personal web use during work, including increased productivity (Coker, 2011), positive emotions (Lim \& Chen, 2012), alleviation from boredom and stress, 
and greater work engagement (Garrett \& Danziger, 2008a; Eastin, Glynn \& Griffiths, 2007; Oravec, 2002).

Coker (2011) showed that in a study on office workers, Youtube video consumption accounted for about $20 \%$ of cyberloafing in a given workday. Combining the numbers at hand, it is reasonable to assume that adult office workers spend about 23 minutes per day on Youtube during work ( $20 \%$ of 1.92 hours). Even though this number is only an approximation from the data at hand, it is reasonable to assume that watching Youtube videos during work is a relevant activity, bearing the question about its recovery potential and media's impact on well-being.

\section{Positive and Meaningful Media Experiences}

Traditionally, entertainment research focused on exploring the effects of hedonically oriented media on mood regulation (e.g., Mood Management Theory; Zillmann, 1988) and need satisfaction (Rubin, 1983). However, those models had difficulties to explain the enjoyment of sad and poignant or dramatic entertainment. Thus, more recent theoretical developments have suggested a two-factor model of entertainment (Vorderer, 2011) that, in addition to a hedonic and purely pleasurable dimension, also includes an eudaimonic dimension that captures more complex media experiences than pleasure, such as mixed affect, inspiration, and feeling tender or moved (i.e., elevation; Oliver, Hartmann, \& Woolley, 2012). Thus, people not only seek out entertainment fare to experience pleasure and avoid unpleasant mood states (Zillmann, 1988), but they also seek out entertainment to experience a sense of appreciation (Oliver \& Bartsch, 2011) and obtain a sense of purpose in life and feelings of meaningfulness (Oliver \& Raney, 2011). For example, when exploring a breadth of entertainment experiences in a series of studies, Oliver and Bartsch (2011) found a clear two- 
factor structure comprising of a factor associated with fun and arousal (i.e., hedonic entertainment experiences) and a second factor comprised of thought-provoking and moving forms of entertainment experiences. Along the same lines, Wirth, Hofer and Schramm (2012) further explicated eudaimonic entertainment experiences and established a comprehensive eudaimonic entertainment experience scale, which includes facets of purpose in life, autonomy, competence/personal growth, relatedness, and the activation of central values. Also, Oliver et al. (2012) showed that recalling a meaningful versus pleasurable entertainment experience resulted in different affective experiences with the former being associated with experiences of elevation and mixed affect (that includes the experience of positive and negative emotions at the same time) and the latter with pleasure and amusement.

Recently, many studies concentrated on elevation as one very prototypical eudaimonic media experience. Elevation is associated with feeling moved, tender, touched, and feeling a lump in the throat and warmth in the chest (Oliver et al., 2012, Haidt, 2003). It is elicited when witnessing acts of moral beauty, such as altruism and kindness, and motivates to emulate the virtuous behavior and prosocial actions (Algoe \& Haidt, 2009; Freeman, Aquino \& McFerran, 2009). For example, Oliver et al. (2012) found that feeling elevated from recalling a meaningful movie motivated people to become a better person and seek what really matters in life.

As mentioned, elevation is one of many potential prototypical eudaimonic media experiences. A related concept to elevation that has not received any attention in the media psychological literature so far is gratitude. Gratitude, is defined as an appreciation for the positive in the world and the good things that happen in life (Park, Peterson, \& Seligman, 2004; Wood, Froh and Geraghty, 2010), and is elicited when we see that other people have 
been helpful, intentionally improved one's own or another person's well-being, or have generally acted morally (Frederickson, 2004; McCullough, Kilpatrick, Emmons, \& Larson, 2001). The experience of gratitude has also been associated with generally greater well-being and greater helping behavior (Bartlet \& DeSteno, 2006). In the limited amount of studies that social psychologists have done to investigate the concept of gratitude in the context of media use, it appears that elevation and gratitude often co-occur. For example, Algoe and Haidt (2009) found that participants exposed to a meaningful (primarily elevation eliciting) video experienced greater warmth and gratitude, in addition to elevation, compared to an admiration and fun video. Diessner et al. (2013) report the same findings with another elevation eliciting video. Consequently, we assume not only that eudaimonic entertainment can indeed elicit gratitude in addition to elevation but also that these experiences may even be more prototypical for meaningful affect than elevation alone. In a general sense, both, elevation and gratitude are elicited by portrayals of goodness or virtue found outside of ourselves, often in other people and their behaviors. In videos we find on the internet, or media content in general, portrayals of moral beauty and kindness and expressions of gratitude and appreciation of that portrayed kindness often go hand in hand. Consequently, we conceptualize meaningful affect in our study as the co-occurrence of elevation and gratitude and as an indicator of eudaimonic entertaintment. Also, we expect this meaningful affect to elicit effects that go beyond the mere entertainment experience, such as effects on recovery and well-being.

\section{Positive Effects of Entertaining Media}

With regard to recovering from stress and work strain, recent research started to explore the relationship between entertainment media use during and after work and recovery experiences and well-being. For example, Reinecke (2009a, b) showed that playing games 
during work and off-work is associated with all four recovery experiences as established by Sonnentag \& Fritz (2007). He also found that people with greater work-related fatigue experienced more recovery from gameplay during and after work (Reinecke 2009a,b).

Extending these findings, Reinecke et al. (2011) showed that the use of both interactive and a non-interactive entertaining media content not only predicted recovery experiences but also well-being, indicated by energetic arousal as assessed with wakefulness (i.e., vitality), as well as increased cognitive performance. Relatedly, Rieger, Reinecke, and Bente (2015) found similar effects of entertaining movie scenes on experiencing recovery and subsequent wellbeing indicators of vitality and cognitive performance.

Researchers illuminated two distinct pathways through which recovery and subsequent vitality as an indicator of well-being could become manifest: While hedonic entertainment experiences were found to foster psychological detachment and relaxation, eudaimonic entertainment experiences were additionally able to contribute to the experience of mastery. These dimensions, in turn, were found to positively predict vitality (Rieger, Reinecke, Frischlich, \& Bente, 2014).

In sum, this evidence suggests that entertainment media (hedonic and eudaimonic) can elicit recovery experiences and thereby contribute to the improvement of well-being. However, these studies also point towards gaps in the literature that are important to consider: First, only Reinecke (2009b) explored media induced recovery experiences during work, and only in a German sample. Second, Rieger et al. $(2014,2015)$ have been the only researchers exploring the different modes of entertainment media (i.e., hedonic and eudaimonic) on psychological well-being. However, using eudaimonic and hedonic entertainment experiences as sole predictors for recovery experiences and well-being, the researchers were unable to 
make predictions about what specific forms of affect are responsible for the effects. This is important, because if we want to make practical recommendations from this type of research, assessing specific affective experiences instead of overall entertainment experiences is important. For example, if we want to recommend specific content for employees to watch for the purpose of recovery and well-being, we could do so better knowing which affective experience that content needs to elicit (i.e., moral beauty for elevation and gratitude). Since the most basic distinction between hedonic and eudaimonic experiences is made by defining hedonic experiences as being elicited together with positive affect, and eudaimonic experiences as being associated with meaningful affect, we focused on these underlying affective experiences in our study.

Third, the aforementioned studies relied only on vitality as an approximate well-being indicator. While the results provided seem promising to suggest positive outcomes for wellbeing after media consumption, other, more direct indicators of well-being have been neglected so far.

Thus, the current study extends this work by employing an experimental study in the workplace, investigating the effects of specific positive affect and meaningful affect inducing Youtube clips on employees' recovery experience, vitality, and work-satisfaction.

\section{Hypotheses}

First, we were interested in the role that online videos play for employees' recovery experiences. Thus, we relied on the media recovery experience model introduced by Rieger et al. (2014) to build our model predicting vitality and work satisfaction at the work-place. Rieger et al. (2014) predicted and tested a fully mediated model of hedonic and eudaimonic media experiences predicting three recovery experiences (psychological detachment, 
relaxation, and mastery experiences), which in turn predicted vitality. Their results indicated that when controlling for hedonic entertainment experiences — which predicted psychological detachment and relaxation-eudaimonic entertainment experiences only predicted recovery in terms of mastery experiences. Considering meaningful affect as an indicator of eudaimonic entertainment experiences and positive affect as an indicator of hedonic entertainment experiences we predicted:

H1a: Positive affect, but not meaningful affect, will predict the recovery experience of psychological detachment.

H1b: Positive affect, but not meaningful affect, will predict the recovery experience of relaxation.

$\mathrm{H} 2$ : Meaningful affect, but not positive affect, will predict the recovery experiences of mastery.

Additionally, Rieger et al. (2014) found that all three recovery experiences predicted vitality (even though in their final model the path between relaxation and vitality had to be eliminated due to multicollinearity problems). Vitality, as assessed with the concept of energetic arousal (Thayer, 1989), is an indicator of successful recovery and subjective wellbeing (Ryan \& Frederick, 1997). Consequently, applying Rieger et al.’s (2014) laboratory results to a natural work context, we predicted:

H3: Recovery experiences of a) psychological detachment b) relaxation, and c) mastery will predict vitality.

Moreover, our study extends the assessment of subjective well-being indicators by including work satisfaction as another outcome of well-being in our model. Work satisfaction is derived from the concept of life satisfaction which is defined as a cognitive judgmental 
process of one's life's circumstances to one's standard (Diener, Emmons, Larsen, \& Griffin, 1985). Work satisfaction, then, is the perception of one's work as fulfilling, meaningful, and self-worth increasing (Parker \& Hyett, 2011). Consequently, the more cognitively detached one is from work related stress and arousal, the more can people see the bigger picture of their work and the impact they have at work, which consequently can lead to greater satisfaction with their work. Further, stress has been shown to be inversely related to life satisfaction (e.g., Chang, 1998). Thus, it can be assumed that relaxation, which is associated with a decrease in stressful arousal states, can be positively related to work satisfaction. Lastly, eudaimonic entertainment, which is associated with meaningful affect, provides many opportunities for self-development, reflection, and personal growth (Wirth et al., 2012). Knobloch-Westerwick, Gong, Hagner, and Kerbeykian (2013) showed how tragedy movies lead to enjoyment through reflecting upon one's life, counting one's blessings, and remembering life goals, among others. Thus, enjoyment is the result of successfully mastering the rather challenging storyline of eudaimonic media that research pointed out (i.e., Bartsch \& Scheider, 2014). Applied to our context, it is reasonable to assume that mastery experiences may potentially maximize one's positive feelings toward and satisfaction with work, based on feeling selfefficacious and in a positive mood after mastering a challenging eudaimonic media experience. Consequently, we predicted:

H4: Recovery experiences of a) psychological detachment, b) relaxation, and c) mastery will predict work satisfaction

As far as the direct connection between entertainment experiences and indicators of well-being are concerned, Rieger et al. (2014) found a significant correlation between hedonic experiences as well as eudaimonic experiences and vitality. Consequently, equating hedonic 
entertainment experience with positive affect and eudaimonic entertainment experiences with meaningful affect, we predicted:

H5a: Positive affect will predict vitality

H5b. Meaningful affect will predict vitality

Lastly, based on the research findings of media based recovery experiences and its relationship to well-being indicators (Reinecke et al., 2011, Rieger et al., 2015) we wanted to investigate the direct mediation of the recovery variables on work satisfaction and vitality in relation to the media experiences. More specifically, vitality and work satisfaction could be summarized under the concept of subjective well-being, which has been defined as the combination of positive affect, low negative affect and high life satisfaction (Diener, 1984). Vitality was found to be significantly correlated with life satisfaction, positive and negative affect (Ryan \& Frederick, 1997). Work satisfaction, in our case, is a specific measure of life satisfaction in the context of work. In fact, Newman, Tay, and Diener, (2014) demonstrated a theoretical relationship between leisure, including recovery experiences and subjective wellbeing. Based on these findings, we explored the following research question:

RQ1: Will recovery experiences function as mediators of the effects of mediated meaningful and positive affect on work satisfaction and vitality?

The research question will help us determine what role mediated affect compared to recovery experiences (as a result of this mediated affect) play for work related well-being.

\section{Method}

\section{Procedure}

An experimental design with three conditions was employed to test our predictions about the effects of online videos at the workplace on recovery experience and work well- 
being. The online experiment was approved by the IRB of the University of Arkansas, 02.02.2016,\#1509115. A Qualtrics online panel was conducted recruiting a sample of $N=$ 148 full-time employees. Two screening questions were employed to ensure a) that participants took the survey while at work (including home office) and b) having worked for at lest 4 hours to ensure a minimum of work strain. Qualtrics programmed the survey so that participants were excluded from participation if they indicated they were not at work and have worked less than 4 hours up to the point of taking the survey. In addition, we asked them again how many hours they have worked until the pint of taking the survey. Overall, $37 \%$ of the participants worked for four hours and 58\% over four hours before taking the survey. 5\% of our sample indicated in the screening question that they did work more than 4 hours but then indicated that indeed they did work less than 4 hours before taking the survey. However, the analysis did not differ with or without these participants in the sample, which is why we included them in our analyses.

The average stress level of participants at the time of taking the survey was 51.28 (SD $=28.22$ ) on a scale from 1 "not stressed at all" to 100 "very stressed"(one item). Furthermore, participants did not have the opportunity to fast forward or skip the video by means of hiding the "next" button until the end of the video and eliminating the control buttons in the video itself. They were instructed to watch the video completely. $11 \%(n=22)$ of the sample indicated that they did something besides watching the video (e.g., eating, checking phone or smoking). ${ }^{1}$ Participants were randomly assigned to one of the three experimental conditions: a) one of two meaningful videos $(n=39)$, b) one of two funny videos $(n=51)$, or c) a control video condition $(n=58)$. Participants within each condition randomly saw one of the two

\footnotetext{
${ }^{1}$ The subsequent analysis did not find any difference in the entertainment experiences between the people that indicated to have multitasked compared to others.
} 
videos. Participants in the control condition watched a 4 minute slideshow of different nature scenes with music, but without any narrative or storyline. This stimulus material for the control condition was adapted from a study by Rieger et al. (2015) and was chosen, so our results can be referred back to the specific videos we used. A control condition without video exposure would have carried too many unknown variables to make inferences about the recovery potential of our different types of videos. All videos lasted about approximately 4 minutes and were downloaded from Youtube and presented without advertising pop-ups.

\section{Demographics}

The sample of $N=148$ full time employees consisted of $47 \%$ females (gender was equally distributed between conditions, $\chi^{2}(4)=4.04, p=.400$ ) with an age range between 20 and 68 years $(M=36.26, S D=10.72)$ that did also not differ between conditions $(F<1)$. Our sample consisted of $65.5 \%$ White, 16.2\% Black, 9.5\% Hispanic/Latin American, $4.7 \%$ Asian/Pacific Islander, 2\% Native American/American Indian participants, and 2\% responded as other. A large majority of the sample $(84 \%)$ indicated that they watched online videos during work. More specifically, 30\% indicated to watch online videos approximately 1-2 times a week, 19\% indicated to watch them 3-4 times a week, 19\%, 5-6 times a week and 17\% said they would watch online videos all the time.

\section{Stimulus Material Selection}

To select the videos for the main study, a pretest was employed to select videos that elicit meaningful and positive affect.

A total of 24, 3-5 minute videos were selected for the pretest, 18 based on their theoretical ability to elicit meaningful affect (including elevation and gratitude experiences, i.e., touching, thankful); and six for their hedonic nature (referred to as "fun" videos, i.e., 
joyful, upbeat). Using Qualtrics, six blocks were created, each containing four of the 24

videos, which were equally randomized between participants. Each participant was exposed to 4 videos in random order.

A total of $N=105$ participants recruited from introductory courses at a university setting took part in the pretest $\left(58 \%\right.$ female, $\left.M_{a g e}=19.22, S D=1.68\right)$ for the exchange of extra credit. After each video, participants responded to items measuring positive affect, elevation and gratitude adopted from Oliver et al. (2012) and McCullough, Tsang and Emmons, (2004) on a 7-point scale from 1 "not at all" to 7 "very much". Additionally, we measured physiological indicators that previously have been associated with hedonic (i.e., light/bouncy, high energy) or eudaimonic content (i.e., lump in throat, warmth of chest, cf. Algoe \& Haidt, 2009). The videos with the highest respective scores (meaningful and positive affect) on each scale and lowest on the other, were selected for the main study. The selected meaningful videos were not significantly different in their elicitation of gratitude and elevation, supporting our assumption that elevation and gratitude are likely two overlapping concepts that together describe meaningful affect. Both meaningful videos differed significantly in their elicitation of positive compared to meaningful affect (gratitude and elevation), as well as in eudaimonic physiological experiences, which were significantly greater than hedonic physiological experiences. In turn, the funny videos were significantly more funny than meaningful and elicited more hedonic physiological responses than eudaimonic ones. Table 1 summarizes the results of the pretest for the selected videos.

----Table 1 here ----

\section{Measures}

Affect. To measure a subset of emotional experiences, four subscales were adopted 
from Oliver et al., (2012) and McCullough, et al., (2004), to measure positive affect, negative affect, and meaningful affect. An exploratory factor analysis using promax rotation (due to a high intercorrelation of .836 of two of the resulting factors) resulted in the expected factor structure of three factors explaining $66 \%$ of variance. The first factor included all 12 elevation and gratitude items measuring meaningful affect (e.g. touched, moved, inspired, thankful, fortunate $\alpha=.959$ ); the second factor included 4 items measuring positive affect (cheerful, happy, upbeat, joyful $\alpha=.888$ ) and the third factor included also 4 items, capturing negative affect (e.g. sad, gloomy, depressed, $\alpha=.816$ ). A mixed affect score was calculated for the manipulation check, using the positive and negative affect scales following the MIN procedure by Ersner-Hershfield, Mikels, Sullivan, and Carstensen’s (2008).

Recovery Experiences. Recovery experiences were measured using the psychological detachment ( $\alpha=.760,4$ items - e.g. "I distanced myself from my work"), relaxation $(\alpha=$ $.835,4$ items - e.g., "When I watched the video: I used the time to relax"), and mastery ( $\alpha=$ $.859,4$ items - e.g. "I did something to broaden my horizon") subscale from Sonnentag and Fritz’s (2007). ${ }^{2}$

Vitality. Vitality was assessed with five items from the tiredness subscale of the Activation-Deactivation-Checklist (Thayer, 1989). Participants were asked to indicate to what extent they felt sleepy, tired, drowsy, wide-awake, and wakeful at the moment. Negative items were reversely coded so that higher scores represented higher levels of energy and wakefulness $(\alpha=.913)$.

Work Satisfaction. A subscale from the work-place well-being questionnaire related to work satisfaction by Parker and Hyett (2011) was used. This subscale consisted of six items

\footnotetext{
${ }^{2}$ The fourth dimension of recovery experiences, namely control experiences, was not assessed in this study, as it was found to primarily be affected by interactive media stimuli (Reinecke et al., 2011; Rieger et al., 2014).
} 
showing a high internal consistency $(\alpha=.949)$. Sample items are "My work is fulfilling" and "My work brings me satisfaction".

\section{Manipulation Check}

\section{Results}

Prior to testing our hypotheses, a manipulation check was conducted to test whether the experimental manipulation of inducing different levels of meaningful and positive affect was successful in our sample. A series of $t$ tests on each video per condition indicated no significant difference between both fun videos on positive affect, and both meaningful videos on meaningful affect. Consequently, we combined the two videos per condition for the analysis.

An ANOVA analysis across conditions indicated that the meaningful condition differed significantly from the fun and control condition in their experiences of meaningful affect. However, the meaningful condition did not differ significantly from the fun condition in positive affect. This finding is consistent with other studies (i.e., Oliver \& Raney, 2011) that have shown how meaningful media content is not only appreciated as meaningful but also as hedonically enjoyable. Thus, the non-significant difference is actually not surprising. In fact, what research so far has pointed out is that meaningful media content is different from funny media content in mixed affective experiences, which includes experiencing positive and negative emotions at the same time (i.e., Oliver \& Bartsch, 2011; Rieger et al., 2014). In fact, our data indicates a marginally significantly greater mixed affect in the meaningful compared to the fun condition, as well as significantly greater negative affect. Consequently, following the literature that defines meaningful media experiences to contain both, positive and negative affect, we regard the stimulus manipulation of eliciting meaningful affect as a form of 
eudaimonic entertainment and positive affect as a form of hedonic entertainment as successful. Table 2 summarizes the results.

----Table 2 here ----

\section{Test of Hypotheses}

To analyze Hypotheses 1-5 that predicted a specific relationship between meaningful and positive affect, recovery experiences, and well-being at the workplace, a path model was computed with the MPlus 5.2 statistical package using the maximum likelihood method. To account for the significant zero-order correlation between the recovery experiences and the emotional media experiences, respectively, we allowed the error terms of these variables to covary within the model. Figure 1 summarizes the model.

---- Figure 1 here ----

The model, including all direct predicted paths as per the hypotheses, fit the data very well without further specification $\left(\chi^{2}=9.518 d f=8, p=.300, \mathrm{RMSEA}=.036,90 \%\right.$ CI $[.000$ $.107], \mathrm{CFI}=.996, \mathrm{SRMR}=.030$ ). As per the manipulation check, the meaningful media condition but not the funny condition predicted meaningful affect significantly $(\beta=.310, p$ $<.001)$. In relationship to the first part of our model, recovery experiences of psychological detachment $(\beta=.387, p<.001)$ as well as of relaxation $(\beta=.585, p<.001)$ were predicted by positive affect supporting $\mathrm{H} 1 \mathrm{a}$ and $\mathrm{H} 1 \mathrm{~b}$. Mastery recovery experiences were predicted by meaningful affect only, as expected in $\mathrm{H} 2(\beta=.649, p<.001)$.

The second part of the model concerned the relationship between recovery experiences and subjective well-being indicators of vitality and work satisfaction (H3, H4). Vitality was only predicted by mastery experiences $(\beta=.287, p=.003)$, supporting H3c. However, H3a and $\mathrm{H} 3 \mathrm{~b}$ did not receive support. Work satisfaction in turn, was only predicted by relaxation 
( $\beta=.294, p=.001)$ supporting $\mathrm{H} 4 \mathrm{~b}$; mastery experiences (H4c) only predicted work satisfaction marginally significantly $(\beta=.166, p=.064)$. H4a, however, was not supported. Table 3 represents the zero-order correlations between variables, as they were included in the model.

----Table 3 here ----

In opposition to Hypothesis 5a and 5b, neither positive affect nor meaningful affect predicted vitality. To investigate the indirect relationships between the variables as questioned in RQ1, a bootstrap analysis using 1000 bootstrap samples and bias-corrected confidence intervals was performed. It revealed that mastery experiences fully mediated the relationship between meaningful affect and vitality $(\beta=.186, p=.010,95 \%$ CI [.038 .323]). Additionally, recovery experiences of relaxation mediated the relationship between positive affect and work satisfaction $(\beta=.162, p=.008,95 \%$ CI [.033 .291]). Lastly, psychological detachment was not a significant mediator for any of the well-being variables.

\section{Discussion}

The aims of the present study were a) to investigate the recovery potential of entertainment media for employees in real working settings, b) to extend previous work on the recovery potential of eudaimonic and hedonic media by specific affective experiences, namely positive and meaningful affect, and c) to explore work satisfaction as an additional indicator for subjective well-being as impacted by recovery experiences.

We found a clear pattern for meaningful and funny videos to influence recovery and well-being. Whereas meaningful content seemed to increase levels of energy at work through mastery recovery experiences, satisfaction with work resulted from watching funny videos that made people feel relaxed. Our data demonstrated that meaningful affect, as a result of 
watching a meaningful video, contributed to recovery experiences of mastery, whereas positive affect, as a result of watching a funny video, predicted psychological detachment and relaxation. First, our findings further support the two-factor model of entertainment (Vorderer, 2011), pointing out the different experiential states of entertainment as well as the differentiating effects that go beyond the entertainment experience. Second, our findings replicate and extend previous laboratory research that has addressed the effects of general hedonic and eudaimonic entertainment experiences on recovery (Rieger et al., 2014, 2015). Meaningful media content seems to particularly pertain to mastery recovery experiences, whereas hedonic, funny content helps people to relax and psychologically detach from work.

Overall, our data illustrate a unique potential of mediated meaningful experiences, that are happy and sad in nature, versus purely positive experiences to elicit a comprehensive set of recovery experiences at work, including recovery through psychological detachment, relaxation, and mastery. Whereas funny cat videos may be enjoyable to watch and even increase positive emotions and energy and decrease negative emotions and feeling drained and tired (Gall Myrick, 2015), they do not seem to be well suited to replenish any internal resources such as self-efficacy or positive moods, as moving and thought-provoking clips may do: Our data point out that hedonic media experiences (positive affect) are not related to the more cognitively demanding recovery dimension of mastery experiences. Thus, whereas lighthearted entertainment seems to be relaxing and distracting in nature, it does not lead to recovery through feelings of competence and psychological growth. Meaningful media content, in contrast, may present a cognitive and emotional challenge to the viewer to master the more complex story line and manage their opposing emotional experiences (mixed affect). Upon completion of such meaningful mediated stories the viewer may experience a feeling of 
accomplishment, which increases their mood and feelings of self-efficacy, and thus aids their recovery.

The second part of our model (H2, H3) explored the differential effects of recovery experiences as direct responses to media stimuli on the subjective well-being indicators of vitality and work-satisfaction. Considering former research (Rieger et al., 2014), it seems that the association between psychological detachment and vitality, and also the one between relaxation and vitality (though significant in the zero-order correlations) do not explain enough variance in a broader path model. Instead, only mastery experiences predict vitality, a relationship that was also significant in Rieger et al's model (2014). This can be explained by the rationale that mastery experiences represent successful coping with a challenge, as outlined, which also has an activating effect (Sonnentag et al., 2008). This may be particularly relevant in a work environment where deep relaxation and complete detachment from the work tasks at hand could even be detrimental for the remaining work-day. Instead, mastery experiences, as a result of watching short meaningful videos, seem to be particularly energizing for employees who lack taking breaks at work, providing them with a feeling of competence to master the work challenges ahead. This relationship may be the reverse in a private context after-work. There, a recharging through cognitive detachment and physiological deactivation (relaxation) may be more important to feel replenished and energized than the experience of personal growth (mastery experience). Future research is needed to better understand the role different contexts play for each individual recovery experience and their impact on well-being.

For work satisfaction, the second indicator of subjective well-being as defined in this study, only relaxation was a significant predictor in the model. Work satisfaction is defined as 
a state in which employees see their work as fulfilling, increasing their sense of self-worth, and advancing their skills (among others, see Parker \& Hyett, 2011). Thus, it makes sense that in order to feel fulfilled, self-worthy, capable, and effective at work (Parker \& Hyett, 2011), a relaxed body and positive affect are important. In fact, Huelsheger and colleagues (2013) showed that mindfulness, defined as non-judgmental present moment awareness, decreased emotional exhaustion at work and increased job satisfaction. One mechanism explaining this finding is the increased activity in the parasympathetic nervous system (i.e., Ditto, Eclache, \& Goldman, 2006): the part of our autonomous nervous system responsible for relaxation. It can be argued that a relaxed physiological state and the positive appraisal of this relaxation experience could also potentially make one more aware of the present moment - representing a state of mindful awareness - which then extends to a positive evaluation of one's work situation (i.e., work satisfaction). Future research is warranted to investigate the relationship between recovery experiences and mindfulness further.

Recovery mastery experiences were a marginally significant predictor for satisfaction with work. It can be argued, that a recovery one perceives through mastering a more challenging media exposure (eudaimonic entertainment) is not only activating in nature (vitality) but also relates to feelings of self-efficacy, fulfillment, and therefore, satisfaction at work. Psychological detachment, however, after controlling for the other recovery experiences, seems less crucial for either of the subjective well-being variables, supporting previous findings by Rieger et al. (2014). One of the mechanisms for psychological detachment is indeed not to think about work, which goes contrary to contemplating one's satisfaction with work. Thus, the recovery component of psychological detachment may be more relevant for well-being in a leisure context. 
Lastly, besides testing this overall path model, direct effects between the positive and meaningful affect and well-being, and the mediating role of recovery experiences were considered (H5, RQ). The results demonstrated only a marginally significant direct effect of meaningful affect on work satisfaction. In fact, the recovery experiences fully mediated the relationship between affective media experiences and subjective well-being indicators. Mastery experiences fully mediated the relationship between meaningful affect and vitality and relaxation mediated the relationship between positive affect and work satisfaction. These results provide additional support for the application of the theory of recovery (Sonnentag \& Fritz, 2007) to the media and immediate work context. Our findings support employer's decisions to foster short video consumption breaks at work (for example in a weekly employee newsletter or internal discussion board) to aid employees' recovery and consequently foster well-being at work.

\section{Limitations}

Although our findings provide new insights into the effects of eudaimonic and hedonic media entertainment experiences on recovery and well-being in a work setting, several limitations have to be noted.

First, while the study extends previous research by implementing two videos per condition, the stimulus material is still limited in its scope. Eudaimonic entertainment experiences include a range of meaningful emotions. We expanded the conceptualization of meaningful affect by measuring gratitude in addition to elevation, but surely this broader measure of meaningful affect is not exhaustive. In addition, eudaimonic entertainment experiences are more complex than hedonic entertainment experiences. That is, they often include mixed affective experiences (e.g., Oliver et al., 2012), which means feeling happy and 
sad at the same time. Consequently, it is hard to experimentally discriminate clearly meaningful content from purely positive content. Our selection of internet videos has high external validity in the sense that these are videos people can see on a regular basis if they chose to do so. Our pretest indeed showed significant differences of the meaningful videos between meaningful and fun affect, however, the student sample may have interpreted the meaningful affect inducing videos differently that the older sample in our main study did. In fact, research shows that age can impact one's perception and preference for meaningful media content (Oliver \& Raney, 2011). Consequently, it is not surprising to see a strong correlation between meaningful and positive media experiences. In fact, it supports the concept of the mixed emotional nature of meaningful content (Oliver et al., 2012; Oliver \& Raney, 2011). Independently, we want to point out that our model supports Rieger et al's (2014) model, despite these shortcoming. With these limitations in mind, it follows, that research on eudaimonic entertainment experiences encounters a specific challenge when determining their impact on media consumers. Future research is warranted to further conceptualize the individual affective experiences subsumed under eudaimonic entertainment experiences and their effects on recovery and well-being indicators.

Second, we only assessed two indicators of well-being, which certainly do not address the full range of well-being indicators that could potentially be relevant in the work context. Besides well-being, the effects of media-induced recovery experiences on cognitive performance are also highly relevant in the work context. Reinecke et al. (2011) showed that exposure to interactive and non-interactive media after experiencing work strain lead to a renewal of cognitive resources and increased cognitive performance through recovery experiences. It remains to be seen what forms of online videos watched during work, hedonic 
or eudaimonic, have a higher potential to increase cognitive functioning through psychological recovery. Additionally, from an organizational standpoint it would be important to explore the role of exposure to online videos at work and behavioral outcomes beyond task performance. For example, future research would benefit the theoretical concept of recovery via media by investigating long-term effects from online video consumption at work on, for example, employee's stress levels, creativity, problem solving capacities or even absenteeism. Third, it can be argued that our experimental design, which provided no choice for participants to select a particular video content, lead to rather conservative effects. Allowing employees to select their own videos could potentially lead to even greater recovery and wellbeing effects due to the feeling of autonomy and recovery control experience (Baard, Deci \& Ryan, 2004; Sonnentag \& Fritz, 2007).

\section{Conclusion}

In conclusion, the study indicates that the use of Youtube videos at work, though frequently considered as cyberslacking with primarily detrimental outcomes by prior research, seems to have positive implications for employees. Funny cat type of videos as well as more moving and meaningful clips that portray the altruistic nature of humanity have specific and independent recovery effects for employees and in turn impact work-place well-being aspects in a particular fashion.

\section{References}

Adler, M. G., \& Fagley, N. S. (2005). Appreciation: Individual differences in finding value and meaning as a unique predictor of subjective well-being. Journal of Personality, 73(1), 79-114. 
Algoe, S. B., \& Haidt, J. (2009). Witnessing excellence in action: The 'other-praising' emotions of elevation, gratitude, and admiration. The Journal of Positive Psychology, $4(2), 105-127$.

American Psychological Association (n.d.). Stress in America. Paying with our health. Retrieved March, 2016 from: https://www.apa.org/news/press/releases/stress/2014/stressreport.pdf

Baard, P. P., Deci, E. L., \& Ryan, R. M. (2004). Intrinsic need satisfaction: A motivational basis of performance and Weil-Being in two work Settings. Journal of Applied Social Psychology, 34(10), 2045-2068.

Bartlett, M.Y., \& DeSteno, D. (2006). Gratitude and prosocial behavior: Helping when it costs you. Psychological Science, 17, 319-325.

Bartsch, A., Kalch, A., \& Oliver, M. B. (2014). Moved to think. Journal of Media Psychology, Theories, Methods, and Applications, 26,125-140. DOI: 10.1027/1864$1105 / a 000118$

Bartsch, A., \& Schneider, F. M. (2014). Entertainment and politics revisited: How nonescapist forms of entertainment can stimulate political interest and information seeking. Journal of Communication, 64, 369-396. doi:10.1111/jcom.12095

Binnewies, C., Sonnentag, S., \& Mojza, E. J. (2010). Recovery during the weekend and fluctuations in weekly job performance: A week-level study examining intra-individual relationships. Journal of Occupational and Organizational Psychology, 83(2), 419-441.

Chancellor, J., Layous, K., \& Lyubomirsky, S. (2015). Recalling positive events at work makes employees feel happier, move more, but interact less: A 6-week randomized 
controlled intervention at a Japanese workplace. Journal of Happiness Studies, 16(4), 871-887. doi:10.1007/s10902-014-9538-Z

Chang, E. (1998). Does dispositional optimism moderate the relation between perceived stress and psychological well being? A preliminary investigation. Personality and Individual Differences, 25, 233-240

Coker, B. L. (2011). Freedom to surf: The positive effects of workplace internet leisure browsing. New Technology, Work and Employment, 26(3), 238-247.

Craig, A., \& Cooper, R. (1992). Symptoms of acute and chronic fatigue. Handbook of Human Performance, 3, 289-339.

Deci, E. L., \& Ryan, R. M. (Eds.). (2002). Handbook of self-determination research. Rochester, NY: University of Rochester Press.

Diener, E. (1984). Subjective well-being. Psychological Bulletin, 95, 542-575.

Diener, E., Emmons, R. A., Larsen, R. J., \& Griffin, S. (1985). The Satisfaction with Life Scale. Journal of Personality Assessment, 49, 71-75.

Diessner, R., Iyer, R., Smith, M., M., Haidt, J. (2013). Who engages with moral beauty? Journal of Moral Education, 42, 139-163.

Ditto B., Eclache M., \& Goldman N. (2006). Short-term autonomic and cardiovascular effects of mindfulness body scan meditation. Annals of Behavioral Medicine, 32, 227-234.

Eastin, M. S., Glynn, C. J., \& Griffiths, R. P. (2007). Psychology of communication technology use in the workplace. CyberPsychology \& Behavior, 10(3), 436-443.

Emmons, R. A., \& McCullough, M. E. (2003). Counting blessings versus burdens: An experimental investigation of gratitude and subjective well-being in daily life. Journal of Personality and Social Psychology, 84(2), 377-389. doi:10.1037/0022-3514.84.2.377 
Ersner-Hershfield, H., Mikels, J. A., Sullivan, S. J., \& Carstensen, L. L. (2008). Poignancy: Mixed emotional experience in the face of meaningful endings. Journal of Personality and Social Psychology, 94, 158-167.

Festinger, L. (1957). A Theory of cognitive dissonance. Stanford, CA: Stanford University Press.

Fredrickson, B. L. (2004). Gratitude, like other positive emotions, broadens and builds. In R. A. Emmons \& M. E. McCullough (Eds.), The Psychology of Gratitude (pp. 145-166). New York, NY: Oxford University Press.

Freeman, D., Aquino, K., \& McFerran, B. (2009). Overcoming beneficiary race as an impediment to charitable donation: Socialdominance orientation, the experience of moral elevation, and donation behavior. Personality and Social Psychology Bulletin, 35, 72-84.

Gallagher, M.W., Lopez, S.J., Preacher, K.J. (2009). The hierarchical structure of well-being. Journal of Personality, 77(4), 1025-1-50.

Garrett, R. K., \& Danziger, J. N. (2008a). Disaffection or expected outcomes: Understanding personal internet use during work. Journal of Computer-Mediated Communication, 13(4), 937-958.

Garrett, R. K., \& Danziger, J. N. (2008b). On cyberslacking: Workplace status and personal internet use at work. CyberPsychology \& Behavior, 11(3), 287-292.

Geraghty, A. W. A., Wood, A. M., \& Hyland, M. E. (2010). Dissociating the facets of hope: Agency and pathways predict dropout from unguided self-help therapy in opposite directions. Journal of Research in Personality, 44(1), 155-158. doi:10.1016/j.jrp.2009.12.003 
Geurts, S. A., \& Sonnentag, S. (2006). Recovery as an explanatory mechanism in the relation between acute stress reactions and chronic health impairment. Scandinavian Journal of Work, Environment \& Health, 482-492.

Greenfield, D. N., \& Davis, R. A. (2002). Lost in cyberspace: The web@work. CyberPsychology \& Behavior, 5(4), 347-353.

Haidt, J. (2003). Elevation and the positive psychology of morality. In C.L.M. Keyes \& J. Haidt (Eds.), Flourishing: Positive psychology and the life well-lived (pp. 275-289). Washington, DC: American Psychological Association.

Hu, L. -T., \& Bentler, P.M. (1999). Cutoff criteria for fit indexes in covariance structure analysis: Conventional criteria versus new alternatives. Structural Equation Modeling, 6, 1-55. doi: 10.1080/10705519909540118

Hülsheger, U. R., Alberts, H. J., Feinholdt, A., \& Lang, J. W. (2013). Benefits of mindfulness at work: The role of mindfulness in emotion regulation, emotional exhaustion, and job satisfaction. Journal of Applied Psychology, 98(2), 310-325.

Kaplan, S., Bradley-Geist, J., Ahmad, A., Anderson, A., Hargrove, A., \& Lindsey, A. (2014). A test of two positive psychology interventions to increase employee well-being. Journal of Business \& Psychology, 29(3), 367-380. doi:10.1007/s10869-013-9319-4

Keyes, C. L. M. (1998). Social well-being. Social Psychology Quarterly, 121-140.

Khoo, G. S. (2016), Contemplating Tragedy Raises Gratifications and Fosters SelfAcceptance. Human Communication Research, 42, 269-291. doi: 10.1111/hcre.12074

Knobloch-Westerwick, S., Gong, Y., Hagner, H., \& Kerbeykian, L. (2012). Tragedy viewers count their blessings: Feeling low on fiction leads to feeling high in life. Communication Research, 40(6), 747- 766. 
Lanham, M. E., Rye, M. S., Rimsky, L. S., \& Weill, S. R. (2012). How gratitude relates to burnout and job satisfaction in mental health professionals. Journal of Mental Health Counseling, 34(4), 341-354.

Lim, V. K., \& Chen, D. J. (2012). Cyberloafing at the workplace: Gain or drain on work? Behaviour \& Information Technology, 31(4), 343-353.Doi 10.1080/01449290903353054

Lundberg, U. (2005). Stress hormones in health and illness: The roles of work and gender. Psychoneuroendocrinology, 30(10), 1017-1021.

Mastrangelo, P. M., Everton, W., \& Jolton, J. A. (2006). Personal use of work computers: Distraction versus destruction. CyberPsychology \& Behavior, 9(6), 730-741.

McCullough, M. E., Kilpatrick, S. D., Emmons, R. A., \& Larson, D. B. (2001). Is gratitude a moral affect? Psychological Bulletin, 127, 249-266.

McCullough, M. E., Tsang, J., \& Emmons, R. A. (2004). Gratitude in intermediate affective terrain: Links of grateful moods to individual differences and daily emotional experience. Journal of Personality and Social Psychology, 86(2), 295-309. doi:10.1037/00223514.86.2.295

Meijman, T. F., Mulder, G., Drenth, P., \& Thierry, H. (1998). Psychological aspects of workload. Handbook of Work and Organizational Psychology.Volume, 2.

Newman, D.B., Tay, L., \& Diener, E. (2014). Leisure and subjective well-being: A model of psychological mechanisms as mediating factors. Journal of Happiness Studies, 15(3), 555-578. DOI 10.1007/s10902-013-9435-x

Nicholls, J. G. (1984). Achievement motivation: Conceptions of ability, subjective experience, task choice and performance. Psychological Review, 91(3), 328-346. 
Oliver, M. B., \& Bartsch, A. (2010). Appreciation as audience response: exploring entertainment gratifications beyond hedonism. Human Communication Research, 36, 5381.

Oliver, M. B. \& Bartsch, A. (2011). Appreciation of entertainment. The importance of meaningfulness via virtue and wisdom. Journal of Media Psychology: Theories, Methods, and Applications, 23, 29-33.

Oliver, M. B., Hartmann, T., \& Woolley, J.K. (2012). Elevation in response to entertainment portrayals of moral virtue. Human Communication Research, 38, 360-378

Oliver, M. B., \& Raney, A. A. (2011). Entertainment as pleasurable and meaningful: Identifying hedonic and eudaimonic motivations for entertainment consumption. Journal of Communication, 61, 984-1004.

Oravec, J. A. (2002). Constructive approaches to internet recreation in the workplace. Communications of the ACM, 45(1), 60-63.

Parker, G. B., \& Hyett, M. P. (2011). Measurement of well-being in the workplace: The development of the work well-being questionnaire. The Journal of Nervous and Mental Disease, 199(6), 394-397. doi:10.1097/NMD.0b013e31821cd3b9

Reinecke, L. (2009a). Games at work: The recreational use of computer games during working hours. Cyberpsychology \& Behavior, 12(4), 461-465.

Reinecke, L. (2009b). Games and recovery: The use of video and computer games to recuperate from stress and strain. Journal of Media Psychology: Theories, Methods, and Applications, 21(3), 126-142. doi:10.1027/1864-1105.21.3.126

Reinecke, L., Klatt, J., \& Krämer, N. C. (2011). Entertaining media use and the satisfaction of recovery needs: Recovery outcomes associated with the use of interactive and 
noninteractive entertaining media. Media Psychology, 14(2), 192-215.

doi:10.1080/15213269.2011.573466

Rieger, D., Reinecke, L., Frischlich, L., \& Bente, G. (2014). Media entertainment and WellBeing — Linking hedonic and eudaimonic entertainment experience to Media-Induced recovery and vitality. Journal of Communication, 64(3), 456-478. doi:

\subsection{1/jcom.12097}

Rieger, D., Reinecke, L., \& Bente, G. (2015). Media-induced recovery: The effects of positive versus negative media stimuli on recovery experience, cognitive performance, and energetic arousal. Psychology of Popular Media Culture, doi:10.1037/ppm0000075

Rieger, D., Kneer, J., Frischlich, L., Wulf, T., Rutkowski, O., \& Bente, G. (2015, May). Enhancing Vitality - Physiological Evidence for the Recovery Potential of Entertaining Movies. Paper presented at the 64th Annual International Communication Association Conference. San Juan: Puerto Rico.

Rosso, B. D., Dekas, K. H., \& Wrzesniewski, A. (2010). On the meaning of work: A theoretical integration and review. Research in Organizational Behavior, 30, 91-127.

Rubin, A.M. (1983). Television uses and gratifications: The interactions of viewing patterns and motivations. Journal of Broadcasting and Electronic Media, 27, 37-51.

Ryan, R. M., \& Deci, E. L. (2001). On happiness and human potentials: A review of research on hedonic and eudaimonic well-being. Annual Review of Psychology, 52, 141-166.

Ryan, R. M., \& Deci, E. L. (2000). Self-determination theory and the facilitation of intrinsic motivation, social development, and well-being. American Psychologist, 55(1), 68-78.

Ryan, R. M., \& Frederick, C. (1997). On energy, personality, and health: Subjective vitality as a dynamic reflection of well-being. Journal of Personality, 65(3), 529-565. 
Ryff, C. D. (1989). Happiness is everything, or is it: Explorations on the meaning of psychological wellbeing. Journal of Personality and Social Psychology, 57, 1069-1081.

Seligman, M. E. P., Steen, T. A., Park, N., \& Peterson, C. (2005). Positive psychology progress: Empirical validation of interventions. American Psychologist, 60(5), 410-421. doi:10.1037/0003-066X.60.5.410

Sheldon, K. M., \& Lyubomirsky, S. (2006). Achieving sustainable gains in happiness: Change your actions, not your circumstances*. Journal of Happiness Studies, 7(1), 5586. doi:10.1007/s10902-005-0868-8

Siltaloppi, M., Kinnunen, U., \& Feldt, T. (2009). Recovery experiences as moderators between psychosocial work characteristics and occupational well-being. Work \& Stress, 23(4), 330-348.

Sluiter, J. K., de Croon, E.M., Meijman, T. F., \& Frings-Dresen, M. (2003). Need for recovery from work related fatigue and its role in the development and prediction of subjective health complaints. Occupational and Environmental Medicine, 60 Suppl 1, i62-i70.

Sonnentag, S., Binnewies, C., \& Mojza, E. J. (2008). " Did you have a nice evening?" A daylevel study on recovery experiences, sleep, and affect. Journal of Applied Psychology, 93(3), 674.

Sonnentag, S., Binnewies, C., \& Mojza, E. J. (2010). Staying well and engaged when demands are high: The role of psychological detachment. Journal of Applied Psychology, 95(5), 965. 
Sonnentag, S., \& Fritz, C. (2007). The recovery experience questionnaire: Development and validation of a measure for assessing recuperation and unwinding from work. Journal of Occupational Health Psychology, 12(3), 204.

Sonnentag, S., \& Zijlstra, F. R. (2006). Job characteristics and off-job activities as predictors of need for recovery, well-being, and fatigue. Journal of Applied Psychology, 91(2), 330.

Steger, M. F., Dik, B. J., \& Duffy, R. D. (2012). Measuring meaningful work: The work and meaning inventory (WAMI). Journal of Career Assessment. doi: 1069072711436160.

Thayer, R. E. (1989). The biopsychology of mood and arousal. New York, NY, US: Oxford University Press.

Van den Broeck, A., Vansteenkiste, M., De Witte, H., \& Lens, W. (2008). Explaining the relationships between job characteristics, burnout, and engagement: The role of basic psychological need satisfaction. Work \& Stress, 22(3), 277-294.

van Hooff, M. L., Geurts, S. A., Beckers, D. G., \& Kompier, M. A. (2011). Daily recovery from work: The role of activities, effort and pleasure. Work \& Stress, 25(1), 55-74.

Vorderer, P. (2011). What's next? Remarks on the current vitalization of entertainment theory. Journal of Media Psychology, 23, 60-63. doi: 10.1027/1864-1105/a000034.

Websense.com (n.d.). Statistics on Cyberloafing. Retrieved March, 2016 from: http://www.siop.org/Media/News/loafing.aspx

Wirth, W., Hofer, M., \& Schramm, H. (2012). Beyond pleasure: Exploring the eudaimonic entertainment experience. Human Communication Research, 38(4), 406-428. doi: 10.1111/j.1468-2958.2012.01434.x.

Wood, A. M., Joseph, S., \& Maltby, J. (2008). Gratitude uniquely predicts satisfaction with life: Incremental validity above the domains and facets of the five factor model. Personality and Individual Differences, 45(1), 49-54. 
Wood, A. M., Froh, J. J., \& Geraghty, A. W. A. (2010). Gratitude and well-being: A review and theoretical integration. Clinical Psychology Review, 30(7), 890-905. doi:10.1016/j.cpr.2010.03.005.

Zijlstra, F., Cropley, M., \& Rydstedt, L. (2014). From recovery to regulation: An attempt to reconceptualize 'recovery from work'. Stress and Health, 30(3), 244-252.

Zillmann, D. (1988). Mood management through communication choices. American Behavioral Scientist, 38(4), 406-428. doi: 10.1177/000276488031003005. 
Table 1.

Means, Standard Deviations and Corresponding Significant t Test Result for Pretest Videos Videos Meaningful $1 \quad$ Meaningful 2 Funny $1(n=12) \quad$ Funny $2(n=20)$ $(n=20) \quad(n=15)$ $M(S D) \quad M(S D) \quad M(S D) \quad M(S D)$

\begin{tabular}{lcccc}
\hline Gratitude $(\alpha=.93)$ & $5.28(1.48)^{\mathrm{a}}$ & $5.05(1.72)^{\mathrm{a}}$ & $2.44(1.36)^{\mathrm{b}}$ & $3.30(1.66)^{\mathrm{b}}$ \\
Elevation $(\alpha=.92)$ & $5.52(1.56)^{\mathrm{a}}$ & $5.55(1.49)^{\mathrm{a}}$ & $2.17(1.42)^{\mathrm{b}}$ & $3.23(1.42)^{\mathrm{c}}$ \\
Positive Affect & $3.95(1.65)^{\mathrm{a}}$ & $3.61(1.63)^{\mathrm{a}}$ & $4.50(1.66)^{\mathrm{b}}$ & $5.00(1.52)^{\mathrm{b}}$ \\
$(\alpha=.90)$ & $2.23(1.12)^{\mathrm{a}}$ & $2.01(1.23)^{\mathrm{a}}$ & $3.12(1.36)^{\mathrm{b}}$ & $4.32(1.55)^{\mathrm{c}}$ \\
Hedonic Physio. & & & \\
$(\alpha=.79)$ & $3.74(1.34)^{\mathrm{a}}$ & $3.81(1.43)^{\mathrm{a}}$ & $1.98(1.31)^{\mathrm{b}}$ & $3.39(1.82)^{\mathrm{ca}}$ \\
Eudaimonic Physio. & & & \\
$(\alpha=.85)$ &
\end{tabular}
Note. Different subscripts within rows indicate significant differences between videos on $p<$ .05. Hedonic Physio = Hedonic Physiological Indicators, Eudaimonic Physio. $=$ Eudaimonic Physiological Indicators (cf. Oliver et al., 2012). See Appendix for the list of videos.

Table 2 . 
Means and Standard Deviations Separated by Experimental Condition and Between Group ANOVA Results

\section{Condition}

\begin{tabular}{llllll}
\hline Meaningful & Fun & Control & & \\
$M(S D)$ & $M(S D)$ & $M(S D)$ & $F(2,145)$ & $p$ & $\eta^{2}$ \\
$\mathrm{n}=39$ & $\mathrm{n}=51$ & $\mathrm{n}=58$ & & &
\end{tabular}

Emotion

\begin{tabular}{|c|c|c|c|c|c|c|}
\hline Meaningful Aff. & $5.86(1.14)^{\mathrm{a}}$ & $4.84(1.46)^{b}$ & $4.61(1.15)^{b}$ & 12.19 & $<.001$ & .144 \\
\hline Positive Affect & $5.29(1.47)^{\mathrm{a}}$ & $5.43(1.34)^{\mathrm{a}}$ & $4.46(1.18)^{b}$ & 8.56 & $<.001$ & .106 \\
\hline Mixed Affect & $3.39(1.63)^{\mathrm{a}}$ & $2.66(1.49)^{\mathrm{b}^{\wedge}}$ & $2.97(1.17)^{a b}$ & 2.87 & .060 & .038 \\
\hline Negative Affect & $3.64(1.78)^{\mathrm{a}}$ & $2.72(1.58)^{b}$ & $3.22(1.40)^{a b}$ & 3.86 & .023 & .051 \\
\hline Ps. Detachment & $5.01(1.42)^{\mathrm{a}}$ & $5.08(1.31)^{\mathrm{a}}$ & $5.04(1.06)^{\mathrm{a}}$ & .042 & .959 & .001 \\
\hline Relaxation & $5.15(1.17)^{\mathrm{a}}$ & $5.45(1.21)^{\mathrm{a}}$ & $5.17(1.10)^{\mathrm{a}}$ & 1.03 & .360 & .014 \\
\hline Mastery & $5.19(1.29)^{\mathrm{a}}$ & $4.04(1.88)^{b}$ & $4.37(1.49)^{b}$ & 6.03 & .003 & .077 \\
\hline Vitality & $4.93(1.37)^{\mathrm{a}}$ & $4.54(1.66)^{\mathrm{ab}}$ & $4.23(1.61)^{b}$ & 2.35 & .099 & .031 \\
\hline Work Sat. & $5.51(1.36)^{\mathrm{a}}$ & $5.41(1.43)^{\mathrm{a}}$ & $5.44(1.36)^{\mathrm{a}}$ & .054 & .947 & .001 \\
\hline \multirow{2}{*}{\multicolumn{7}{|c|}{$\begin{array}{l}\text { Note. Meaningful Aff. = Meaningful Affect. Ps. Detachment = Psychological Detachment. } \\
\text { Work Sat. = Work Satisfaction. The significance value has been Least Significant Difference }\end{array}$}} \\
\hline & & & & & & \\
\hline \multicolumn{7}{|c|}{ (LSD) and Games-Howell adjusted depending on the non homogeneity of variance. Different } \\
\hline \multicolumn{7}{|c|}{ subscripts within rows indicate significant differences between conditions at $p<.05$. $^{\mathrm{b}^{\wedge}}=p<$} \\
\hline
\end{tabular}


Table 3.

Zero Order Correlation for All Path Model Variables

\begin{tabular}{lcccccc}
\hline & 1 & 2 & 3 & 4 & 5 & 6 \\
\hline 1. Positive Affect & - & & & & & \\
2. Meaningful Affect & $.74 * *$ & - & & & & \\
3. Psychological Detachment & $.39 * *$ & $.34 * *$ & - & & & \\
4. Relaxation & $.58^{* *}$ & $.46^{* *}$ & $.42^{* *}$ & - & & \\
5. Mastery & $.49^{* *}$ & $.65^{* *}$ & $.29 * *$ & $.43^{* *}$ & - & \\
6. Vitality & $.30^{* *}$ & $.36^{* *}$ & .08 & $.20 *$ & $.39 * *$ & - \\
7. Work Satisfaction & $.43^{* * *}$ & $.47 * *$ & $.33^{* *}$ & $.49 * *$ & $.45^{* *}$ & $.45^{* *}$ \\
\hline
\end{tabular}

Note. ${ }^{*} p<.05, * * p<.001$ 


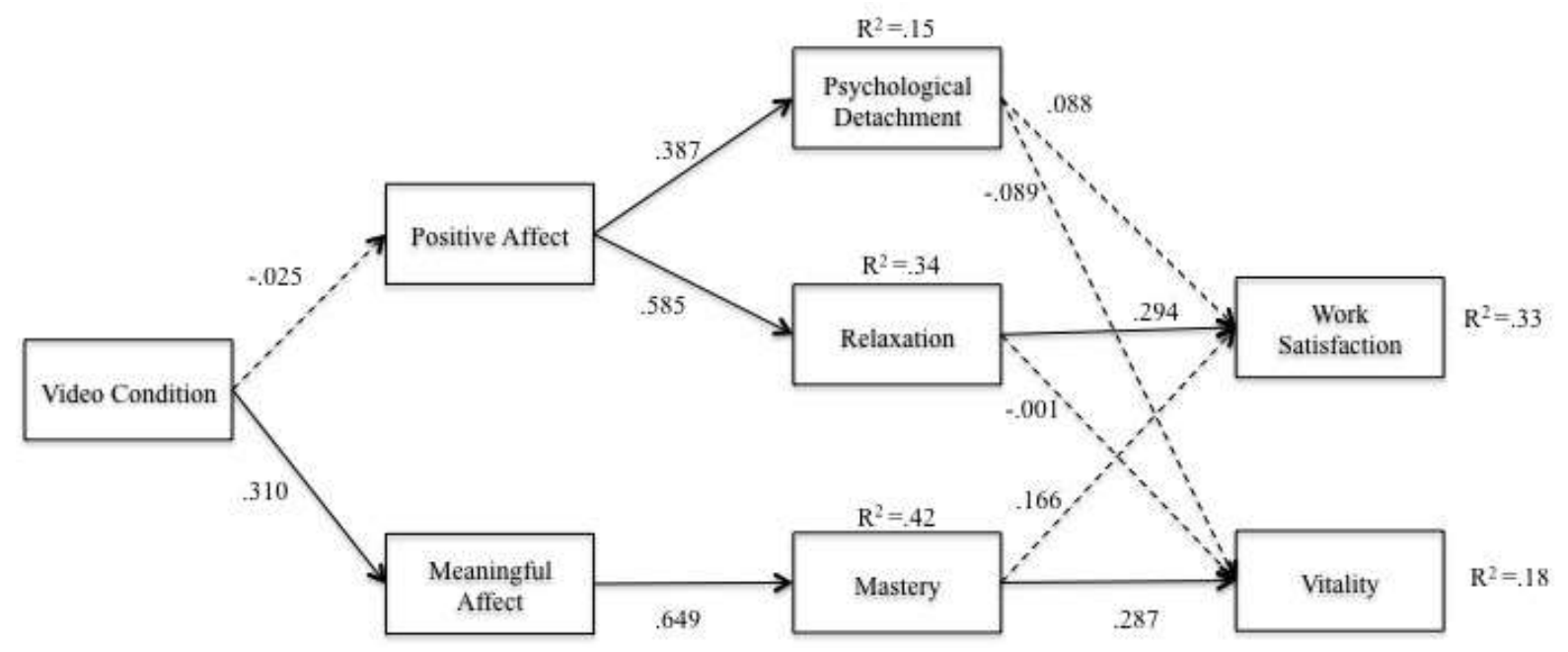

Figure 1. Final path model $(N=90)$. Solid arrows represent significant standardized path coefficients $(p<.05)$, dotted arrows represent insignificant paths $(p>.05)$ as tested in the hypotheses. Model fit was based on Hu and Bentler's (1999) recommended fit indices: CFI $>.95$, RMSEA <.06, SRMR <.09. Video condition was coded as $0=$ fun, $1=$ meaningful. The control condition was not included in the final path model analysis. 


\section{Appendix}

Meaningful video 1 (3.02 min): https://www.youtube.com/watch?v=0YLVBIT0GDQ

The video is a commercial for an insurance company in Thailand, showing a child stealing medicine for his sick mother and being met with kindness by the store vendor who gave him the medicine for free and let him go. 30 years later the child, then adult, pays the favor forward.

Meaningful video 2 (3.5 min): https://www.youtube.com/watch?v=ege3YJ_01H8 This video is a news report about a boy finding $\$ 20$ bill in a parking lot and instead of spending it on himself he gave it to a soldier he met at a grocery store with a note thanking him for his service.

Funny video 1 (3.34 min): https://www.youtube.com/watch?v=TQwmME2SI9E The video shows different animals dancing to music. Note. Due to a termination of the account that uploaded the dancing animal video we used for the study, we can no longer provide the exact video used in the study. Instead we included a working link to a video highly similar to the one used in the study.

Funny video 2 (3.25 min): https://www.youtube.com/watch?v=v9oxyswY8fs The video shows babies making funny faces and noises. 